\title{
ACIDENTES MOTOCICLISTICOS E AÇÕES EDUCATIVAS NO TRÂNSITO EM MUNICÍPIO DO ESTADO DE MATO GROSSO
}

Flávio Bispo de Liraㄹ, Cibele Martins dos Santos Ulle, Magda de Mattos ${ }^{1}$

Objetivo: caracterizar os acidentes motociclisticos atendidos pelo Serviço de Atendimento Móvel de Urgência (SAMU) nos anos de 2014 e 2015 e descrever as ações de educação no trânsito. Metodologia: estudo documental, descritivo, com abordagem quantitativa, em que realizou-se a análise das ocorrências de atendimentos do SAMU nos anos de 2014 a 2015 e as ações educativas realizadas no município de Rondonópolis, estado de Mato Grosso. Resultados: Dados evidenciaram predominância do sexo masculino, na faixa etária de 18 a 35 anos em ambos os anos pesquisados, destacando-se colisões entre carro e moto, no horário entre às 06:00 e 17:59 horas. As ações educativas realizadas focaram em palestras de direção defensiva e teatro com fantoches à educação infantil. Conclusão: destaca-se um aumento do número de acidentes envolvendo motocicletas de 2014 para 2015, atingindo jovens adultos do sexo masculino e poucas atividades educativas para um trânsito mais seguro. Descritores: Motocicletas; Morbidade; Serviços Médicos de Emergência; Acidentes de Trânsito.

\section{MOTORCYCLICAL ACCIDENTS AND EDUCATIONAL ACTIONS IN TRANSIT IN MUNICIPALITY OF THE STATE OF MATO GROSSO}

Objective: To characterize the motorcycle accidents attended by the Mobile Emergency Care Service (SAMU) in the years 2014 and 2015 and describe the actions of education in traffic. Methodology: A descriptive, descriptive study with a quantitative approach, in which the analysis of the occurrences of SAMU services in the years 2014 to 2015 and the educational actions carried out in the municipality of Rondonópolis, state of Mato Grosso, were carried out. Results: Data showed a predominance of males, aged between 18 and 35 years in both years, with car and motorcycle collisions between 06:00 and 17:59 hours. The educational actions carried out focused on defensive direction lectures and theater with puppets to early childhood education. Conclusion: There is an increase in the number of accidents involving motorcycles from 2014 to 2015, reaching young males and few educational activities for safer traffic.

Descriptors: Motorcycles, Morbidity; Emergency Medical Services; Traffic accidents.

\section{ACCIDENTES MOTOCICLISTICOS Y ACCIONES EDUCATIVAS EN EL TRÁNSITO EN MUNICIPIO DEL ESTADO DE MATO GROSSO}

Objetivo: Caracterizar los accidentes motociclísticos atendidos por el Servicio de Atención Móvil de Urgencia (SAMU) en los años 2014 y 2015 y describir las acciones de educación en el tránsito. Metodología: Estudio documental, descriptivo, con abordaje cuantitativo, en que se realizó el análisis de las ocurrencias de atendimientos del SAMU en los años 2014 a 2015 y las acciones educativas realizadas en el municipio de Rondonópolis, estado de Mato Grosso. Resultados: Datos evidenciaron predominancia del sexo masculino, en el grupo de edad de 18 a 35 años en ambos años investigados, destacándose colisiones entre auto y moto, en el horario entre las 06:00 y las 17:59 horas. Las acciones educativas realizadas se enfocaron en conferencias de dirección defensiva y teatro con títeres a la educación infantil. Conclusión: Se destaca un aumento del número de accidentes involucrando motocicletas de 2014 para 2015, alcanzando jóvenes adultos del sexo masculino y pocas actividades educativas para un tránsito más seguro.

Descriptores: Motocicletas; Morbilidad; Servicios Médicos de Emergencia; Accidentes de Tráfico. 


\section{INTRODUÇÃO}

Os acidentes de trânsito têm aumentado de modo significativo, atingindo principalmente pessoas mais vulneráveis, como os pedestres, os ciclistas, os usuários de motocicletas e de ciclomotores, tornando-se, portanto, uma questão de saúde pública, e, consequentemente, uma das principais causas de morbimortalidade mundialmente ${ }^{(1)}$

O aumento da frota de motocicletas tem, entre suas principais causas, o importante papel no deslocamento da população urbana por ser considerado um meio de transporte econômico, rápido e com preço acessivel, se comparado aos automóveis. A frota de motocicleta registrada no território nacional contabiliza mais de 20 milhões e, no estado de Mato Grosso, já são mais de 574 mil (2).

Como consequências dos acidentes com motocicletas, têm-se altos índices de óbitos, que se concentram basicamente na população de 15 a 29 anos e, com impactos fortes também na faixa de 30 a 49 anos. 3 Além dos óbitos, as lesões temporárias e permanentes influenciam negativamente no país com elevado custo social, redução da expectativa de vida, sobrecarga econômica ao Sistema Único de Saúde (SUS) e ao fator previdenciário (4)

Dados da OMS ressaltam que as principais vítimas de óbitos decorrentes dos acidentes no trânsito são os indivíduos jovens e do sexo masculino. Não obstante, estas informações são preocupantes ao se considerar que estas pessoas encontram-se no período mais economicamente produtivo de suas vidas, de forma que a sua morte ou incapacidade afeta as suas famílias em virtude da diminuição ou perda da renda (1).

Estudos têm demonstrado que a maior incidência de acidentes motociclisticos ocorrem durante a semana, no horário compreendido entre às 06:00 e 17:59 horas. Acidentes ocorridos nos finais de semana, nas sextas-feiras há prevalência de vítimas não fatais e nos sábados e domingos, há um aumento de vitimas fatais, principalmente em vias onde não há nenhum tipo de fiscalização que coíba o abuso de velocidade ${ }^{(5-7)}$.

Assim sendo, os acidentes de trânsito com motocicletas podem ser definidos como acontecimentos decorrentes de imperícia, imprudência e negligência, sendo considerados acontecimentos previsiveis e evitáveis. Para tanto, a crescente morbimortalidade exige intervenções que promovam sua redução, visto que a imprudência é a principal causadora desses acidentes pelo fato de os usuários negligenciarem as normas de trânsito(8).

Dentre as causas de imprudência, tem-se o uso de bebidas alcoólicas, principalmente nos finais de semana, em que há uma tendência de ingestão e abuso do consumo pelos condutores. Para tanto, a lei no. 11.705 , de 19 de junho de 2008, alterou o Código de Trânsito Brasileiro e instituiu taxa de alcoolemia zero e impôs penalidades mais severas para o condutor que dirigir sob a influência do álcool, tornando-se uma medida importante para a prevenção de acidentes de trânsito. Igualmente importante é a manutenção e ampliação de medidas como fiscalização, comunicação e educação de forma continuada e sistemática, evitando-se, dessa maneira, retrocessos nos avanços alcançados ${ }^{(9)}$.

Estudos alertam que as inúmeras tentativas de reduzir os altos índices de acidentes no Brasil não estão sendo suficientes, mesmo com legislações de fiscalização e penalização mais severas aos infratores sancionadas pelo Código de Trânsito de 1998 e a lei Seca de 2008. Há, portanto, necessidade da implementação de programas capazes de mudar o comportamento das pessoas no trânsito, de um sistema de informação de qualidade a fim de fornecer informações essenciais para subsidiar pesquisas na área, a implementação de políticas e estratégias de prevenção e promoção da saúde, como também a avaliação das ações, promovendo discussão e educação para o trânsito junto à população ${ }^{(5,10,11)}$.

Diante deste contexto, este estudo tem por objetivo caracterizar os acidentes motociclisticos atendidos pelo Serviço de Atendimento Móvel de Urgência (SAMU) nos anos de 2014 e 2015 e descrever as ações de educação no trânsito.

\section{METODOLOGIA}

\section{Tipo de estudo}

Trata-se de uma pesquisa documental, descritiva, com abordagem quantitativa.

\section{Local de estudo}

O estudo foi realizado no Serviço de Atendimento Móvel de Urgência (SAMU) e na Secretaria Municipal de Transporte e Trânsito (SETRAT) no município de Rondonópolis, localizado na região sudoeste do estado de Mato Grosso.

\section{Coleta de dados}

A coleta das informações ocorreu no período de janeiro a julho de 2017. Foi realizado o levantamento de todos os acidentes de trânsito envolvendo motocicletas na região urbana nos anos de 2014 e 2015 e atendidos pelo SAMU. Os dados foram coletados a partir da consulta manual de todas as fichas de atendimentos no período estabelecido nesta pesquisa, e posteriormente, transcritos para um instrumento específico elaborado pelos pesquisadores, o qual apresentava as seguintes variáveis: 1) dados de caracterização das vítimas, 2) horário e, 3) tipo de acidente.

Os dados referentes às ações de educação no trânsito desenvolvidas no município foram coletados a partir do relatório anual disponibilizado pela Secretaria Municipal de Transporte e Trânsito. Para tanto, elaborou-se instrumento abarcando as 
informações referentes ao tipo de atividade desenvolvida, período e frequência em que foi realizado.

\section{Procedimentos de análise dos dados}

Os dados coletados foram digitados para a organização de um banco de dados utilizando o programa Microsoft Office Exce $^{\circledR}$, versão 2007 e em seguida, realizou-se a análise estatística descritiva.

\section{Procedimentos éticos}

A pesquisa obedeceu rigorosamente aos preceitos éticos regulamentados pela Resolução 466/2012 e foi aprovado pelo Comitê de Ética em Pesquisa da Universidade Federal de Mato Grosso, Parecer no 1.202.378.

\section{RESULTADOS}

No período estudado, a análise do conjunto de todos os atendimentos clínicos e de traumas realizados pelo SAMU no ano de 2014 foi de 4.768 e em 2015, de 7.027. Os dados acima, quando separados por ocorrências que envolveram motocicletas, contabilizaram 2.198 (46,10\%) acidentes em 2014 e, para o ano de 2015, foi de 2.343 (33,34\%). Dentre as pessoas envolvidas nos acidentes com motocicletas, a predominância foi do sexo masculino, com 56,70\% em 2014 e 58,34\% em 2015. No que concerne à faixa etária, observou-se a prevalência de idade compreendida entre os 18 a 35 anos com 65,72\% em 2014, e no ano de 2015 com 66,21\%. Em relação ao horário dos acidentes, o maior número foi entre 06:00 e 17:59 horas, totalizando um percentual de $64,41 \%$ em 2014 , e de $61,80 \%$ em 2015 (Tabela 1).

Tabela 1 - Características dos acidentes motociclisticos ocorridos nos anos de 2014 e 2015.

\begin{tabular}{|c|c|c|c|c|}
\hline \multirow{2}{*}{ Variáveis } & \multicolumn{2}{|c|}{2014} & \multicolumn{2}{|c|}{2015} \\
\hline & $\mathbf{N}$ & $\%$ & $\mathbf{N}$ & $\%$ \\
\hline \multicolumn{5}{|l|}{ Sexo } \\
\hline Masculino & 956 & $56,70 \%$ & 1.367 & $58,34 \%$ \\
\hline Feminino & 562 & $33,33 \%$ & 896 & $38,24 \%$ \\
\hline Não informado & 168 & $9,96 \%$ & 80 & $3,41 \%$ \\
\hline \multicolumn{5}{|l|}{ Idade } \\
\hline 0 a 6 & 28 & $1,51 \%$ & 40 & $1,53 \%$ \\
\hline 7 a 17 & 128 & $6,89 \%$ & 180 & $6,90 \%$ \\
\hline 18 a 25 & 612 & $32,94 \%$ & 795 & $30,46 \%$ \\
\hline 26 a 35 & 609 & $32,78 \%$ & 933 & $35,75 \%$ \\
\hline 36 a 45 & 250 & $13,46 \%$ & 360 & $13,79 \%$ \\
\hline$>46$ & 231 & $12,43 \%$ & 302 & $11,57 \%$ \\
\hline \multicolumn{5}{|l|}{ Horário } \\
\hline 06 as 17:59 & 1086 & $64,41 \%$ & 1.448 & $61,80 \%$ \\
\hline 18 as 05:59 & 600 & $35,59 \%$ & 895 & $38,20 \%$ \\
\hline
\end{tabular}

\section{Tipos de Acidentes}

\begin{tabular}{lcccc}
$\begin{array}{c}\text { Colisão moto/ } \\
\text { carro }\end{array}$ & 857 & $50,83 \%$ & 1.221 & $52,11 \%$ \\
$\begin{array}{c}\text { Queda de moto } \\
\quad 430\end{array}$ & $25,50 \%$ & 602 & $25,69 \%$ \\
$\begin{array}{c}\text { Colisão moto/ } \\
\text { moto }\end{array}$ & 287 & $17,02 \%$ & 375 & $16,01 \%$ \\
$\begin{array}{c}\text { Atropelamento } \\
\text { por moto }\end{array}$ & 50 & $2,97 \%$ & 54 & $2,30 \%$ \\
$\begin{array}{c}\text { Colisão moto/ } \\
\text { ônibus, caminhão, } \\
\text { van }\end{array}$ & 45 & $2,66 \%$ & 60 & $2,56 \%$ \\
$\begin{array}{c}\text { Colisão moto/ob- } \\
\text { jetos fixos }\end{array}$ & 17 & $1,01 \%$ & 31 & $1,32 \%$ \\
\hline
\end{tabular}

Fonte: Serviço de Atendimento Móvel de Urgência. Rondonópolis/MT, 2017.

Em relação às ações educativas no trânsito, os dados demonstraram um aumento no ano de 2015, com 37 ações (Tabela 2).

Tabela 2 - Principais ações de educação no trânsito desenvolvidas no município.

Tipo de Ação

2014

2015

\begin{tabular}{|c|c|c|}
\hline $\begin{array}{l}\text { Palestras: direção defensiva } \\
\text { e segurança de trânsito e } \\
\text { mobilidade urbana }\end{array}$ & 13 & 30 \\
\hline $\begin{array}{l}\text { Teatro com fantoches na } \\
\text { educação infantil }\end{array}$ & 5 & 2 \\
\hline $\begin{array}{l}\text { Projetos agentes de trânsito } \\
\text { mirim e medidas preventivas } \\
\text { de segurança }\end{array}$ & 6 & 1 \\
\hline Curso de direção defensiva & 2 & \\
\hline $\begin{array}{l}\text { Semana do Trânsito com ci- } \\
\text { nema rodoviário }\end{array}$ & 2 & \\
\hline $\begin{array}{l}\text { Atividades pontuais como } \\
\text { campanhas de trânsito SE- } \\
\text { NAI, PRF e Blitz educativa }\end{array}$ & 2 & 3 \\
\hline $\begin{array}{l}\text { Curso/Formatura de agente } \\
\text { de trânsito mirim }\end{array}$ & 1 & 1 \\
\hline Total & 31 & 37 \\
\hline
\end{tabular}

Fonte: Secretaria Municipal de Transporte e Trânsito. Rondonópolis/MT, 2017.

Nota-se que o foco das ações desenvolvidas pela Secretaria Municipal de Transporte e Trânsito foi relacionado às palestras de direção defensiva e teatro com fantoches na educação infantil. A este respeito, constatou-se que o período de execução das ações foi realizado principalmente no segundo semestre dos anos estudados (Tabela 3). 
Tabela 3 - Distribuição das ações de trânsito por trimestre e ano.

\begin{tabular}{lcc} 
Periodo & \multicolumn{2}{c}{ Ano } \\
\cline { 2 - 3 } 1 Trimestre & $\mathbf{2 0 1 4}$ & $\mathbf{2 0 1 5}$ \\
\hline 2ㅇ Trimestre & 0 & 0 \\
3ㅇ Trimestre & 6 & 6 \\
4ㅇ Trimestre & 15 & 12 \\
Total & 14 & 20 \\
\hline
\end{tabular}

Fonte: Secretaria Municipal de Transporte e Trânsito. Rondonópolis/MT, 2017.

\section{DISCUSSÃO}

Os dados obtidos demonstraram o mesmo cenário encontrado em outras regiões do país, com predomínio de jovens adultos e do sexo masculino envolvidos em acidentes de trânsito com motocicletas. Dentre as prováveis causas, destacam-se fatores como a utilização de alta velocidade em vias públicas, o desrespeito às normas de segurança no trânsito, a necessidade de impressionar os amigos, manobras arriscadas e a impulsividade. Ainda, são esses indivíduos que geralmente consomem mais bebidas alcoólicas e drogas ilícitas, o que aumenta as chances de ocorrências de acidentes ${ }^{(4,5,12,13)}$

Diferentemente do sexo masculino, o feminino destacou-se nesta pesquisa pelos índices menores de ocorrências nos acidentes motociclisticos. Resultados semelhantes também foram encontrados em outros estudos e que podem estar relacionados à presença das mulheres como passageiras na motocicleta e, por geralmente, pilotarem utilizando velocidades mais baixas e com manobras menos arriscadas ${ }^{(12,14,15)}$

Um dado relevante refere-se ao número de crianças menores de sete anos envolvidas nos acidentes motociclisticos. Observou-se, nos dois anos pesquisados, o total de 68 crianças, caracterizando infração gravíssima de acordo com a legislação vigente. A prática do transporte de menores de sete anos de idade em motocicletas é ilegal e terminantemente proibida por lei. A presença dessa faixa etária pode estar relacionada ao deslocamento para escola, uma vez que a motocicleta geralmente é o meio de transporte mais acessivel das famílias, visto ser mais econômica e ágil quando comparada ao automóvel (15).

Entre os adolescentes menores de 18 anos, demonstrou-se que 128 (6,89\%), em 2014, e 180 (6,90\%), em 2015, envolveram-se em acidentes motociclisticos. A esse respeito, os adolescentes são legalmente impedidos de conduzir qualquer tipo de veículo automotor, pois não possuem idade suficiente e nem carteira de habilitação. Esses dados constituem informações importantes para o monitoramento de comportamentos em jovens brasileiros e deve subsidiar políticas de promoção à saúde e prevenção desses agravos em adolescentes ${ }^{(16,17)}$.

O período diurno concentrou o maior número de aciden- tes, dado este também observado em outro estudo ${ }^{5}$, e pode ser caracterizado como acidente de trabalho, visto o período entre as 06:00 e 18:00 horas ser aquele em que os trabalhadores encontram-se deslocando-se ao trabalho ou retornando para suas residências. Outro aspecto a ser considerado quanto ao período diurno com maior índice de acidentes, para a OMS, as pessoas que utilizam o trânsito estão mais expostas aos riscos em face da necessidade de se utilizar as vias e pelos volumes e composições do tráfego nelas presentes ${ }^{(1)}$.

No que concerne aos principais tipos de acidentes, houve predominância da categoria colisão de motocicleta com carro, totalizando mais de $50 \%$ em ambos os anos, cujos achados também foram observados em estudo similar ${ }^{(10)}$. Dentre as prováveis causas, poderia ser citada a dificuldade dos condutores de outros veículos em perceberem a proximidade de motocicletas, bem como a utilização de manobras arriscadas e ultrapassagens indevidas que tendem a aumentar as chances de colisões.

Nesse contexto, os motociclistas encontram-se mais vulneráveis às lesões, principalmente devido à exposição corpórea direta à colisão com carros e, portanto, sujeitos aos traumas múltiplos e de maior gravidade.18 A vulnerabilidade dos condutores de motocicletas pode resultar em lesões temporárias ou permanentes, assim interferindo na qualidade de vida e aumentando os gastos públicos ${ }^{(18-21)}$.

Vale considerar que os acidentes motociclisticos são considerados importantes causadores de incapacidades temporárias ou permanentes nas pessoas envolvidas e, além disso, também ocasionam óbitos. Não obstante, esse tipo de acidente de trânsito pode resultar em graves prejuizos ao indivíduo, seja no aspecto financeiro, social ou econômico, como também aos seus familiares ${ }^{(22)}$

O segundo tipo de acidente identificado na pesquisa foi queda de moto, que representou 25,50\% no ano de 2014 e de $25,69 \%$ em 2015, evidenciando-se uma constante neste tipo de ocorrência nos anos estudados. As quedas de motocicletas geralmente estão associadas a fatores como o aumento de veículos em circulação, alta velocidade, disputa das vias por espaços chamados corredores, onde os motociclistas preferencialmente pilotam para evitar os congestionamentos, a precariedade e má sinalização das vias, falta de fiscalização, embriaguez e impunidade para os indivíduos envolvidos nos acidentes ${ }^{(23)}$.

Uma das possibilidades para redução de lesões e sequelas decorrentes de acidentes de trânsito com motocicletas tem como foco o incentivo à população para o uso de transportes de forma mais segura. De acordo com a OMSl, disponibilizar às pessoas um transporte público de qualidade e de baixo custo reduziria consideravelmente o trânsito excessivo de veículos e melhoraria a segurança. Não obstante, é de 
responsabilidade dos gestores públicos o incentivo ao uso de meios de transporte mais seguros, de instituir redução de velocidade em vias com altos índices de acidentes, de informar e orientar os condutores de veículos.

Ao se observar como a gestão municipal tem trabalhado as ações educativas para reduzir os altos índices de acidentes motociclisticos, os dados demonstraram que a atividade mais realizada foi a de palestras com enfoque na direção defensiva, segurança no trânsito e mobilidade urbana, a partir da solicitação de empresas privadas. Desse modo, o estudo sugere que as atividades desenvolvidas não conseguem atingir grande parcela da população. Além disso, essa busca por parte das empresas está diretamente relacionada aos acidentes de percurso, o que vem ao encontro dos principais horários de acidentes encontrados na pesquisa.

A segunda atividade desenvolvida no município foi teatro de fantoches, realizadas na educação infantil, o que resultou em sete ações nos anos de 2014 e 2015. Considerando o número de escolas no município do estudo, disponibilizados pela Plataforma OEdu(24), totalizando 153 instituições (públicas, privadas, municipais, estaduais, zona urbana e rural), observou-se que há uma grande divergência com o total de ações desenvolvidas, que atingiram apenas $4,57 \%$ das escolas, tornando evidente a necessidade de promover ações que abarcam maior número de crianças.

Quanto ao período de concentração de atividades realizadas, principalmente no segundo semestre do ano, e ausência de ações educativas no primeiro trimestre dos dois anos estudados, revela-se provável falta de planejamento por parte dos gestores municipais em relação a uma data importante e que geralmente reúne um número grande de pessoas, como ocorre no Carnaval.

Em concordância com outras pesquisas realizadas que apontaram o trimestre em que ocorreram mais acidentes, os que apresentaram maior número de vítimas foram os que compreendem os períodos de novembro a janeiro e de fevereiro a abril (12,14,24,25). É provável que esses agravos sejam influenciados pelos festejos natalinos e de final do ano. Sabe-se também que o período de férias e das festas pré e pós-carnavalescas funcionam como apelo para o maior consumo de bebidas alcoólicas.

Aponta-se como limitações do presente estudo, que podem ser ajustadas em futuros trabalhos, seria abarcar todos os tipos de acidentes, além dos motociclisticos e ampliação do recorte temporal, tanto para as ocorrências dos acidentes quanto para as ações educativas realizadas pelo município.

\section{Limitações do estudo}

O estudo apresentou limitações referentes a coleta de dados, na qual alguns deles foram descartados por apresentarem preenchimento incorreto das fichas de atendimento e informações incompletas, de forma que dados como profissão e tipo de trauma não puderam ser incluídos na caracterização das vítimas.

\section{Contribuições do estudo para prática}

Pode-se afirmar que este estudo beneficie os serviços de saúde em todos os níveis de atendimento, primário, secundário e terciário, bem como os gestores responsáveis pelas ações de planejamento do município, haja vista que foi possível traçar o perfil das vítimas estudas acometidas por acidentes motociclisticos e os horários com maiores ocorrências, fornecendo informações importantes para elaboração de medidas específicas para esses grupos e fiscalizações preventivas para o controle dessa morbidade.

\section{CONCLUSÃO}

Os dados do estudo permitiram constatar um aumento no índice de acidentes motociclisticos dos anos de 2014 e 2015 , em que as principais vitimas foram adultos jovens e do sexo masculino, no horário diurno.

Embora se tenha observado no município ações educativas com foco em palestras, ainda há necessidade de medidas urgentes e efetivas de educação no trânsito, com finalidade de orientar os condutores de motocicletas. Para tanto, os gestores e profissionais de saúde devem conhecer as informações relativas aos períodos com maior índice de acidentes para que possam desenvolver ações educativas e efetivas.

Desta forma, entende-se que é de extrema importância o planejamento de novas ações educativas, utilização de outras abordagens metodológicas bem como para sensibilizar a população condutora de motocicletas e os demais condutores de veículos automotores.

Por fim, conhecer as características dos acidentes de trânsito com motocicletas mostra-se, não só importante, mas fundamental para que os programas de prevenção sejam formulados e implantados de forma adequada, eficaz e eficiente. 


\section{REFERÊNCIAS}

1. Organização Mundial da Saúde (OMS). Relatório mundial sobre prevenção de lesões causadas pelo trânsito: resumo. 2012.

2. DENATRAN - Departamento Nacional de Trânsito. Relatórios Estatísticos 2017. Brasil; 2017.

3. Campos JR, Do Nascimento ERP, Hermida PMV, Da Silva Galetto SG Rasia MA, Silveira NR. Caracteristicas De Acidentes Por Transporte Terrestre Atendidos Em Hospitais Públicos. Cogitare Enfermagem [Internet]. 2018 [cited 2018 Oct 5]; 23(2). Available from: http:// www.saude.ufpr.br/portal/revistacogitare/wp-content/uploads/ sites/28/2018/05/53094-233973-1-PB.pdf

4. Santos RODS, Andrade SMOD, Martins BSTP. Segurança e mobilidade no trânsito: percepção da população de uma capital do Brasil central. Interações (Campo Grande) [Internet]. 2017 [cited 2018 Oct 12]: 18(4):109-119. Available from: http://www.scielo.br/pdf/inter/ v18n4/1518-7012-inter-18-04-0109.pdf

5. Pavanitto DR, Menezes RADM., Nascimento LFC. Accidents involving motorcycles and potential years of life lost. An ecological and exploratory study. Sao Paulo Medical Journal [Internet]. 2018 [cited 2018 Oct 10]: 136(1):4-9. Available from: http://www.scielo.br/pdf/ spmj/v136nl/1806-9460-spmj-1516-3180-2017-0098070817.pdf

6. Mandacarú PMP, Rabelo IVM, Silva MAAD, Tobias GC, Morais Neto OLD. Óbitos e feridos graves por acidentes de trânsito em Goiânia, Brasil-2013: magnitude e fatores associados. Epidemiologia e Serviços de Saúde [Internet]. 2018 [cited 2018 Oct 7]; 27:e2017295. Available from: https://www.scielosp.org/pdf/ress/2018.v27n2/e2017295/pt

7. Kist Ibiapino M, Couto M, Brito V, Pires Sampaio B, de Souza RAR Andreas Padoin, F, Santana Salomão I. Serviço de atendimento móvel de urgência: epidemiologia do trauma no atendimento pré-hospitalar. Revista da Faculdade de Ciências Médicas de Sorocaba [Internet]. 2017 [cited 2018 Oct 12]; 19(2). Available from: https://revistas.pucsp. br/index.php/RFCMS/article/view/30805/pdf

8. de Sousa LRB, de Sousa GS, da Costa Monroe KCM, Pereira MGS. Notificação do acidente traumático em um hospital público da Amazônia brasileira. Revista Brasileira em Promoção da Saúde [Internet]. 2017 [cited 2018 Oct 5]; 30(1). Available from: http:// periodicos.unifor.br/RBPS/article/view/5891/pdf

9. Abreu DRDOM, Souza EMD, Mathias TADF. Impacto do Código de Trânsito Brasileiro e da Lei Seca na mortalidade por acidentes de trânsito. Cadernos de Saúde Pública [Internet]. 2018 [cited 2018 Oct 7]; 34:e00122117. Available from: https://www.scielosp.org/pdf/ csp/2018.v34n8/e00122117/pt

10. Botelho LJ, Gonzaga HN. Mortalidade por acidentes motociclisticos: Estudo comparativo entre Santa Catarina e Brasil. Boletim do Curso de Medicina da UFSC [Internet]. 2017 [cited 2018 Oct 7]: 3(8). Available from: http://ojs.sites.ufsc.br/index.php/medicina/article/ view/2427/1439

11. Alves CA, Gomes JO. Contribuições da psicologia do trânsito: considerações sobre educação para o trânsito e formação profissional. Revista Científica da FAMINAS [Internet]. 2016 [cited 2018 Oct 10]; 10(3):65-74. Available from: http://periodicos.faminas.edu.br/index. php/RCFaminas/article/view/352/327

12. Mendonça MFSD, Silva APDSC, Castro CCLD. Análise espacial dos acidentes de trânsito urbano atendidos pelo Serviço de Atendimento Móvel de Urgência: um recorte no espaço e no tempo. Revista Brasileira de Epidemiologia [Internet]. 2017 [cited 2018 Oct 9]; 20:727-741. Available from: https://www.scielosp.org/pdf/rbepid/2017.v20n4/727$741 / p t$

13. Damasceno IS, Alves TM, Santos LRO, Fianco MC, Araújo SNM, Silva MNL. Caracterização clínica e epidemiológica de pacientes vitimas de acidentes motociclisticos. Enferm. Foco [Internet]. 2018 [cited 2019 Aug 10]; 9(2):13-17. Available from: http://revista.cofen.gov.br/index.

\section{php/enfermagem/article/view/1131/0}

14. Moutte de Freitas R. Perfil dos acidentes motociclisticos atendidos no hospital de referências e ensino na região sul da cidade de São Paulo. Dissertação (Mestrado em Ciências da Saúde) - UNISA [Internet]. 2017. [cited 2018 Oct 10]. Available from: http://dspace. unisa.br/handle/123456789/173

15. Moreira Corgozinho M, Ângelo Montagner M, Carvalho Rodrigues MA. Vulnerabilidade sobre duas rodas: tendência e perfil demográfico da mortalidade decorrente da violência no trânsito motociclistico no Brasil, 2004-2014. Cadernos Saúde Coletiva [Internet]. 2018 [cited 2018 Oct 5]; 26(1). Available from: http://www.scielo.br/pdf/cadsc/ v26nl/1414-462X-cadsc-26-1-92.pdf

16. Souza HNF, Drumond EF, Malta DC, Costa TAH, Freitas MIF Perspectiva de motociclistas acidentados sobre riscos e acidentes de trânsito. REME - Rev Min Enferm [Internet]. 2018 [cited 2018 Oct 10]; 22:e-1088. Available from: http://www.reme.org.br/artigo/ detalhes/1226

17. Castro LJO, Campos MEA, Mattos GPF, Lage G, Oliveira FAP, Xavier CC. Dirigir moto ou carro entre adolescentes: inquérito "saúde em Vespasiano". Rev Med Minas Gerais [Internet]. 2018 [cited 2018 Oct 10] 28:e-1980. Available from: http://www.rmmg.org/artigo/detalhes/2346

18. Martins MDR, Lorensetti ACCDO. Perfil Epidemiológico Das Vítimas De Acidentes De Trânsito De Maringá-PR. Revista Uningá [Internet] 2018 [cited 2018 Oct 13]; 47(2). Available from: http://revista.uninga.br/ index.php/uninga/article/view/1275/896

19. Silveira JZM, Souza JCRP. Sequelas de Acidentes de Trânsito e Impactos na Qualidade de Vida. Saúde e Pesquisa [Internet]. 2016 [cited 2018 Oct 5]; 9(2):373-380. Available from: http://periodicos. unicesumar.edu.br/index.php/saudpesq/article/view/5255/2850

20. Andrade SSCDA, Jorge MHPDM. Estimate of physical sequelae in victims of road traffic accidents hospitalized in the Public Health System. Revista Brasileira de Epidemiologia [Internet]. 2016 [cited 2018 Oct 13]; 19(1):100-lll. Available from: http://www.scielo.br/pdf/rbepid/ v19nl/1980-5497-rbepid-19-01-00100.pdf

21. Gransotto Filho G. Tendência temporal dos acidentes de trânsito com motocicletas e fatores associados em Santa Catarina. Trabalho de Conclusão de Curso apresentado ao Curso de Graduação em Medicina-Pedra Branca [Internet]. 2017 [cited 2018 Oct 10]. Available from: https://www.riuni.unisul.br/handle/12345/2219

22. Silva RF, Paiva ARDO. Incidência De Acidentes Com Motocicletas No Brasil: Revisão Integrativa Da Literatura. Revista Uningá [Internet] 2018 [cited 2018 Oct 12]; 51(3). Available from: http://revista.uninga.br/ index.php/uninga/article/view/1360/979

23. Santos MRC, Fraga-Maia H. Perfil Epidemiológico das Vitimas de Traumatismo Cranioencefálico Atendidas pelo Samu-Salvador. Revista Pesquisa Em Fisioterapia [Internet]. 2016 [cited 2018 Oct 7]; 6(4):376-378. Available from: https://www5.bahiana.edu.br/index.php/ fisioterapia/article/view/1017/738

24. Barros CHDSA, de Souza Matos TE, Reis JCA, de Oliveira Brandão P, da Silva EMB, da Silva APPA, Tamada H. Perfil das vitimas não fatais atendidas nos hospitais de Porto Velho entre 2015 e 2016, Rondônia Brasil. Journal of Health \& Biological Sciences [Internet]. 2018 [cited 2018 Oct 10]; 6(2):156-164. Available from: http://revistaopiniaojuridica. unichristus.edu.br/index.php/jhbs/article/view/1711/634

25. da Conceição Araújo D, Pinheiro FGDMS, Menezes MGV, Lima SDGS, Tavares CSS, Vaez AC. Perfil e fatores associados ao trauma em vitimas de acidentes de trânsito atendidas por serviço móvel de urgência. Arquivos de Ciências da Saúde [Internet]. 2017 [cited 2018 Oct 10]; 24(2):65-70. Available from: http://www.cienciasdasaude. famerp.br/index.php/racs/article/view/729/692 